\title{
Evaluation of Total Phenolic Content, Total Antioxidant Activity, and Antioxidant Vitamin Composition of Pomegranate Seed and Juice
}

\author{
Anahita $\mathbf{A}^{1^{*}}$, Asmah $\mathbf{R}^{1}$ and Fauziah $\mathrm{O}^{2}$ \\ ${ }^{1}$ Department of Nutrition and Dietetics, Faculty of Medicine and Health Sciences, Universiti Putra Malaysia, 43400, Serdang, Selangor, Malaysia \\ ${ }^{2}$ Department of Human Anatomy, Faculty of Medicine and Health Sciences, Universiti Putra Malaysia, 43400, Serdang, Selangor, Malaysia
}

*Corresponding author: Anahita A, Department of Nutrition and Dietetics, Faculty of Medicine and Health Sciences, Universiti Putra Malaysia-43400, Serdang, Selangor, Malaysia, Tel: +60173972310; E-mail: asmah@upm.edu.my

Rec date: Nov 29, 2014 Acc date: Feb 16, 2015 Pub date: Feb 21, 2015

Copyright: ( 2015 Anahita A, et al. This is an open-access article distributed under the terms of the Creative Commons Attribution License, which permits unrestricted use, distribution, and reproduction in any medium, provided the original author and source are credited.

\begin{abstract}
This study aimed to determine total phenolic content (TPC), total antioxidant activity (TAA), antioxidant vitamin composition (A, C, and $\mathrm{E}$ ) of pomegranate fruit. In addition, two edible parts of pomegranate juice, pomegranate seed, and combination of them were compared based on antioxidant properties. TPC was determined by using Folin-Ciocalteu (FC) method based on colorimetric reduction. Ferric reduction ability power (FRAP assay) was used to test the antioxidant activity. Vitamin assessments were conducted by using high performance liquid chromatography (HPLC). Results for antioxidant vitamin composition in pomegranate juice (PJ) showed that the concentration of vitamin A was $22.8 \pm 0.69 \mu \mathrm{g} / 100 \mathrm{~g}$, vitamin $\mathrm{C}$ was $57.8 \pm 0.59 \mathrm{mg} / 100 \mathrm{~g}$, and vitamin E was $0.07 \pm$ $0.01 \mathrm{mg} / 100 \mathrm{~g}$. Besides, TPC in PJ, pomegranate seed (PS), and pomegranate seed-juice (PSJ) was $2502 \pm 54$, $165 \pm 49$, and $2696 \pm 49 \mathrm{mg} \mathrm{GAE} / \mathrm{L}$, and TAA was $32 \pm 5.1,20 \pm 2.8$, and $47 \pm 5.5 \mathrm{mmol} / \mathrm{L}$ respectively. This study revealed that PSJ contained high level of phenolic compounds, antioxidant activity, and vitamin C. In addition, TPC was as main contributor to antioxidant activities, and positively correlated with TAA $\left(r^{2}=0.91, p<0.05\right)$. Therefore, combination of pomegranate seed and juice may become an alternative and potential source of natural antioxidant.
\end{abstract}

Keywords Antioxidant activity; Phenolic content; Pomegranate; Vitamin composition

\section{Introduction}

Pomegranate (Punicagranatum) is one of the oldest known edible fruit that born on the small long-living tree, which is cultivated through the Mediterranean region, Himalayas, and Southeast Asian [1]. The pomegranate fruit can be divided into three anatomical origins: seeds, peel, and arils. Pomegranate fruit is considered as a nutritious fruit due to its biological actions; most of these effects were attributed to its high phenolic content and vitamin C [2]. Pomegranate juice is obtained from arils, which are rich sources of bioactive compound like phenolic and flavonoids [3]. Another part of pomegranate fruit is seeds, which are a rich origins of polyunsaturated (PUFA) mostly linolenic (n-3), and linoleic (n-2). Phenolic content is the main compound attribute for the most of the functional properties of many fruits such as pomegranate and grapes [4]. Reactive oxygen and nitrogen species are constantly produced in vivo for physiological purposes, and often over-produced in pathological situations cause oxidative damage [5]. All oxygen-consuming organisms are used antioxidant such as vitamin $\mathrm{C}, \mathrm{E}, \mathrm{A}$, and phenolic to protect their possible damage to biological molecules [6]. In the recent years, more attention has been paid to the antioxidants contained in fruits; because epidemiological studies revealed that high fruit intake was associated with reduced mortality and morbidity of some chronic diseases such as cardiovascular diseases, cancers and neurological damage [2].

One of the possible mechanisms was attributed to the antioxidant activity presented infruits [7]. Some phenolic compounds are even more powerful as antioxidants than vitamin $\mathrm{C}, \mathrm{E}$ in vitro, and significantly bioavailable, as demonstrated by animal and human studies [8]. Antioxidants have leading role in health maintenance based on their modulation of the oxidation processes in the body [9]. Consequently the search for inexpensive and abundant sources of natural antioxidants is attracting worldwide interest. Consumption of fresh fruits and vegetables to improve human health has been attributed primarily to their high contents of healthful phytochemicals and other micronutrients [10]. This study was conducted to determine antioxidant power of pomegranate fruit, and tocompare between twoedible parts of pomegranate (juice and seed) based on antioxidant properties.

\section{Materials and Methods}

\section{Chemicals}

L-ascorbic acid, $\alpha$-tocopherol, trans- $\beta$-carotene, Ferric Chloride $\left(\mathrm{FeCl}_{3} \cdot 6 \mathrm{H}_{2} \mathrm{O}\right)$, and TPTZ (2,4,6-tri[2-pyridyl]-s-triazine) were purchased from Sigma-Aldrich (St Louis, Mo., USA). Folin-Ciocalteu reagent was from Merck Chemical Supplies (MerckKGaA, Darmstadt, Germany). Gallic acid was obtained from NacaliaTesque, Kyoto, Japan.

\section{Preparation of samples for analysis}

Ripe sweet red pomegranate fruits were used in this study, were imported from Spain. The fruit was washed, peeled, and stored. The fruit arils were crushed and squeezed by squeezing machine (National Juicer/Blender). The pomegranate juice (PJ) was filtered to remove any water-insolublematerials. Liquid nitrogen and freeze-drying machine was used to make powder from pomegranate juice, and then stored at $-18^{\circ} \mathrm{C}$. The pomegranate seeds (PS) from the juice preparation were freeze dried at $-20^{\circ} \mathrm{C}$ separately and groundinto powder. For 
preparation of pomegranate seed-juice (PSJ), $0.8 \mathrm{~g}$ from PJ powder was added to $0.2 \mathrm{~g}$ of PS powder. About $100 \mathrm{~g}$ of the powder was mixed with $300 \mathrm{ml}$ of $70 \%$ ethanol in distilled water and kept for 3 days at room temperature. The extract was then filtered. Solvent of ethanol was removed by using a rotary evaporator under vacuum at $50^{\circ} \mathrm{C}$. The extract was obtained, and kept in the refrigerator.

\section{Determination of total phenolic content (TPC)}

Total phenolic content was determined according to the method of by using the Folin-Ciocalteu reagent based on colorimetric reduction [11]. The phenolic compounds are oxidized to phenolates by the reagent at alkaline $\mathrm{pH}$ in a saturated solution of sodium carbonate resulting in a blue complex. About $1.5 \mathrm{ml}$ of Folin-Ciocalteau (10\%, $\mathrm{w} / \mathrm{v}$,) is added to $300 \mu \mathrm{l}$ sample, followed by the addition of $1.2 \mathrm{ml}$ of aqueous $\mathrm{Na}_{2} \mathrm{CO}_{3}(7.5 \%$, w/v). The mixture was allowed to stand in the dark for 90 minutes. The absorbance of the blue color solution was read at $760 \mathrm{~nm}$ on a UV visible spectrophotometer (Shimadzu, Kyoto, Japan), against blank (distilled water). Total phenolic concentration $(\mathrm{mg} / \mathrm{ml})$ of the samples were analyzed in triplicates, and extrapolated from a standard curve, constructed by using Gallic acid as a standard. Results were expressed as Gallic acid equivalents (GAE).

\section{Determination of ferric reducing antioxidant power (FRAP) assay}

The FRAP assay was presented as a method for assessing "antioxidant power" according to adapted procedure from [12]. Ferric to ferrous ion reduction at low $\mathrm{pH}$ causes a colored complex. The FRAP reagent was prepared with mixture $200 \mathrm{ml}$ acetate buffer 300 $\mathrm{mM}$ (pH 3.6), $20 \mathrm{ml}$ TPTZ (2,4,6-tri(22-pyridyI)-s-triazine), in $10 \mathrm{ml}$ $\mathrm{HCL}, 40 \mathrm{mM}$; and $20 \mathrm{ml} \mathrm{Fecl}_{3} \cdot 6 \mathrm{H}_{2} \mathrm{O}$ in ratio 10:1:1 to give the working reagent. After preparing, FRAP regent kept in the water bath at $37^{\circ} \mathrm{C}$. Then, $0.5 \mathrm{ml}$ of pomegranate samples were mixed with $1 \mathrm{ml}$ of FRAP regent and $30 \mathrm{ml}$ of distilled water, and reading at $593 \mathrm{~nm}$ by using spectrophotometer (SECOMAN, France). Second reading was performed after 4 minutes at $593 \mathrm{~nm}$. The results were calculated from the standard curve prepared by different concentration of $\mathrm{FeSO}_{4} \cdot 7 \mathrm{H}_{2} \mathrm{O}$, and expressed in $\mathrm{mmol} \mathrm{Fe} \mathrm{F}^{+2} / \mathrm{L}$.

\section{Estimation of $\boldsymbol{\beta}$-carotene (vitamin $\mathrm{A}$ )}

Estimation of $\beta$-carotene (vitamin A) was conducted by using high performance liquid chromatography (HPLC). Extraction of vitamin A was carried out according to the method described by [13]. The sample (10 g) was added with $10 \mathrm{ml}$ of $100 \%(\mathrm{w} / \mathrm{v})$ potassium hydroxide and $40 \mathrm{ml}$ of $99.8 \%$ ethanol and homogenized for 3 minutes. The mixture was saponified by a refluxing apparatus, and then was heated using an electric heating mantle for 30 minutes, and cooled to room temperature. The mixture was agitated frequently to avoid any aggregation. For the extraction step, the mixture was transferred into separatory funnel and then $50 \mathrm{ml}$-hexane was added. The funnel was inverted, and shaken vigorously for a few seconds, and the layer was permitted to separate. The upper layer (hexane extract) was pipetted out and the aqueous layer was extracted twice, each time with $(50 \mathrm{ml})$ of $n$-hexane. Then, the upper layer was washed and pooled with distilled water until free of alkali. Phenolphthalein solution (1\%) was exploited to check for any alkali. The extract was then filtered to remove any water residue through anhydrous sodium sulphate. The hexane residues were removed using rotary evaporator under reduced pressure at $45^{\circ} \mathrm{C}$. The resulting extract was diluted to $(10 \mathrm{ml})$ with HPLC grade-hexane. Samples were conducted in triplicates, and separation condition in Table 1 .The peak of $\beta$-carotene was established based on two techniques: comparing the retention time and spiking test with that of trans- $\beta$-carotene (Sigma, Co. Chemical, St. Louis, USA). $10 \mathrm{mg}$ of trans- $\beta$-carotene was weighed and dissolved in $100 \mathrm{ml}$ pure n-hexane to give a stock solution of $100 \mu \mathrm{g} / \mathrm{ml}$. The solution was stored in a brown bottle and kept as stock in the fridge at $5^{\circ} \mathrm{C}$. The standard solution of $1 \mu \mathrm{g} / \mathrm{ml}$ was prepared daily from the stock solution.

\begin{tabular}{|l|l|l|l|}
\hline Conditions & & & \\
\hline Parameter & Vitamin A & Vitamin C & Vitamin E \\
\hline Moblie phase & $(88: 10: 2)$ & $(50: 50)$ & $(88: 10: 2)$ \\
\hline Flow rate & $1.0 \mathrm{ml} / \mathrm{min}$ & $1.5 \mathrm{ml} / \mathrm{min}$ & $1.0 \mathrm{ml} / \mathrm{min}$ \\
\hline Detection & $250 \mathrm{~nm}$ & $254 \mathrm{~nm}$ & $250 \mathrm{~nm}$ \\
\hline
\end{tabular}

Table 1: HPLC conditions for separation and identification of vitamin $\mathrm{A}, \mathrm{C}$, and $\mathrm{E}$

\section{Estimation of ascorbic acid (vitamin C)}

Ascorbic acid (vitamin C) was conducted by using high performance liquid chromatography (HPLC). The sample was thoroughly cleaned using deionized water to remove adhering contaminants and estimation was done on the same day of purchase to counteract the instability of vitamin $\mathrm{C}$ in fruits. Extraction for ascorbic acid analysis was obtained by homogenizing $10 \mathrm{~g}$ of the sample in solution containing $20 \mathrm{ml}$ meta-phosphoric acid $(0.3 \mathrm{M})$, and acetic acid $(1.4 \mathrm{M})$. The mixture was located in conical flask (wrapped with aluminum foil), and agitated at $100 \mathrm{rpm}$ with an orbital shaker for 15 minutes at room temperature [14]. The mixture collected was filtered through Whatman (No. 4) filter paper (Milipore, USA), and $30 \mu \mathrm{l}$ in triplicates was immediately used for HPLC analysis. The techniques were used to identify the peak of vitamin $\mathrm{C}$ on the chromatogram; comparing the retention time and spiking test with that of L-ascorbic acid (Sigma, Co. Chemical, St. Louis, USA). Ascorbic acid standard was prepared by dissolving $100 \mathrm{mg}$ of $\mathrm{L}$-ascorbic acid in a metaphosphoric acid $(0.3 \mathrm{M})$ and acetic acid $(1.4 \mathrm{M})$ solution at the final concentration of $1 \mathrm{mg} / \mathrm{ml}$.

\section{Estimation of $\alpha$-tocopherol (vitamin E)}

Estimation of $\alpha$-tocopherol (vitamin E) was conducted by using high performance liquid chromatography (HPLC). Extraction for vitamin $\mathrm{E}$ was obtained according to the method described by Amin, Cheah and Abdulnabi [14,15]. $5 \mathrm{mg}$ of sample was added with $20 \mathrm{ml}$ methanol. Then, the mixture was mixed with $60 \mathrm{ml} \mathrm{CCl}_{4}$ methanol (3:1) and agitated at $100 \mathrm{rpm}$ with an orbital shaker for 20 minutes. The $\mathrm{CCl}_{4}$ fraction was separated from the aqueous phase in a separatory funnel, and dried over $\mathrm{Na}_{2} \mathrm{SO}_{4}$. Rotary evaporator was exploited to evaporate the filtrate to dryness under pressure $45^{\circ} \mathrm{C}$. The extract lipid fraction was saponified by refluxing in the presence of $(0.5 \mathrm{~g})$ ascorbic acid with $4 \mathrm{ml}$ of $30 \%$ methanolic potassium hydroxide $(\mathrm{KOH})$ for 30 minutes at the boiling point of methanol. After cooling, the flask at room temperature $15 \mathrm{ml}$ of salted water added and the analogues of tocopherol were extracting twice with 40 $\mathrm{ml}$ petroleum ether in a separator funnel. The ether fractions were washed twice with distilled water, collected, and dried over anhydrous sodium sulphate $\left(\mathrm{Na}_{2} \mathrm{SO}_{4}\right)$. Rotary evaporator was exploited to evaporate the solvent at $45^{\circ} \mathrm{C}$. The residues were dissolved in $5 \mathrm{ml}$ of 
HPLC grade hexane. The vitamin E determined by a reverse-phase HPLC technique. Samples were conducted in triplicates, and separation conditions in Table 1. The peak for vitamin $\mathrm{E}$ also recognized based on comparing the retention time and spiking test what that of $\alpha$-tocopherol (Sigma, Co. Chemical, St Louis, USA). 10 $\mathrm{mg}$ of $\alpha$-tocopherol was weighed and dissolved in pure $\mathrm{n}$-hexane to give stock solution $100 \mu \mathrm{g} / \mathrm{ml}$. The solution was stored in a brown bottle and kept as stock in the fridge at $5^{\circ} \mathrm{C}$.

\section{Statistical analysis}

All data were reported as mean \pm S.E.M of triplicate determination. One-way analysis of variance (ANOVA) with significant differences between means determined at $\mathrm{p}<0.05$, measured with post-hoc multiple comparisons and Tukey's test were performed with SPSS (version 21, IBM U.S.A). In addition, Pearson correlation was used to demonstrate the correlation between total antioxidant activity and total phenolic content.

\section{Results and Discussion}

\section{Total phenolic content}

The total phenolic content (TPC) of pomegranate was determined through analysis of Folin-Ciocalteau method that it is shown in Table 2. One-way ANOVA test was conducted to explore the level of phenolic content between PS, PJ, and PSJ, as measured by Gallic acid. Post-hoc comparison using the Tukey HSD test indicated that the mean score for PSJ was significantly $(\mathrm{p}<0.05)$ different from group PS and PJ. Moreover, The PSJ(2696 $\pm 49 \mathrm{mgGAE} / \mathrm{L})$ exhibited high amount of TPC. This value for PJ was the same range for red wine (generally above $2000 \mathrm{mg} / \mathrm{L}$ ), and twice that found in green tea $(1029 \pm$ 36) [16]. The total phenolic calculated for pomegranate juice reached $2100 \mathrm{mg} / \mathrm{L}$, which was good in agreement with the Folin-Ciocalteu method. This finding showed that PSJ has high level of total phenolic content compared to other fruits juice such as orange and berries, even red wine. Besides, TPC in PSJ was higher than two other parts (PS and PJ) separately.

Epidemiology studies have demonstrated that consumption of fruits and vegetables with high phenolic content correlated with reduction of cardiovascular, cerebrovascular diseases, and cancer mortality [17]. Phenolic compounds in pomegranate may produce their beneficial effects by scavenging free radicals [2].

\begin{tabular}{|l|l|l|}
\hline Parameter & TAA & TPC \\
\hline Pomegranate juice (PJ) & $32 \pm 5.1^{\mathrm{a}}$ & $2502 \pm 54^{\mathrm{a}}$ \\
\hline Pomegranate seed (PS) & $20 \pm 2 .^{8 \mathrm{~b}}$ & $165 \pm 49^{\mathrm{b}}$ \\
\hline Pomegranate seed + juice (PSJ) & $47 \pm 5.5^{\mathrm{c}}$ & $2696 \pm 49^{\mathrm{c}}$ \\
\hline
\end{tabular}

Table 2: Total antioxidant activity (TAA) of pomegranate by FRAP assay and Total phenolic content (TPC) by Folin-Ciocalteu method. Values were expressed as mean \pm S.E.M $(n=3)$, different lowercase letters indicate significant difference at $\mathrm{p}<0.05$

\section{Total antioxidant activity}

The antioxidant activity of pomegranate was determined by using FRAP assay, which was ferric reducing antioxidant power (FRAP) that it is shown in Table 2. ANOVA test was conducted to explore the level of antioxidant activity between PS, PJ, and PSJ as measured by FRAP value. Post-hoc comparison using the Tukey HSD test indicated that the mean score TAA forPSJ $\left(47 \pm 5.5 \mathrm{mmol} / \mathrm{L} \mathrm{Fe}^{+2}\right)$ was significantly $(\mathrm{p}<0.05)$ different from PS, and PJ. The antioxidant activity of Pomegranate components has been reported in the many studies [18-20]. The antioxidant capacity of pomegranate juice was shown to behigher than red wine, and green tea, based on the evaluation of the free radicals scavenging activity, and iron reducing capacity of the juice [16]. Furthermore, fruits have relationship between, antioxidant composition, and antioxidant activity, and those with high antioxidant activity generally contain more antioxidants [7]. Current study proved that pomegranatefruits were a rich possessed source of dietary antioxidants. Moreover, these nutrient characteristics are more significant in PSJ compared to other parts of pomegranate (seed or juice) separately.

\section{Correlation between total antioxidant activity (TAA) and total phenolic content (TPC)}

Data were obtained from this survey showed strong correlation between antioxidant activity and total phenolic content (Figure 1). Statistical analysis showed that there are strong positive correlation between TAA and TPC (Pearson correlation $\mathrm{r} 2=0.91$ at $\mathrm{p}<0.05$ ). Phenolic contentmight act as important contributor of antioxidant activity effect in PJ.

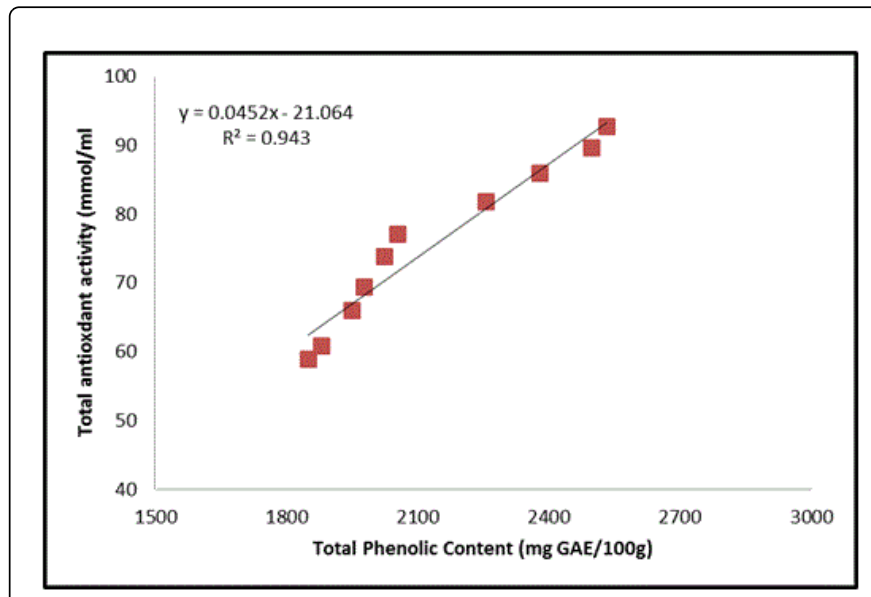

Figure 1: Linear correlation between the amount of total phenolic content and total antioxidant activity, coefficient of determination $\mathrm{R}^{2}=0.943$, correlation is significant at 0.05

\section{Antioxidant vitamins composition}

Antioxidant vitamins composition in pomegranate was measured by HPLC and the results are summarized in Table 3. Results showed that pomegranate juice could be a complimentary source of vitamin $\mathrm{C}$ and $\mathrm{A}(58 \pm 0.6 \mathrm{mg} / 100 \mathrm{~g}, 22.8 \pm 0.7 \mu \mathrm{g} / 100 \mathrm{~g})$. These concentrations are comparable to other fruits or vegetables such as apples, apricots, carrots, cherries, or peaches and better than plums or pears [21]. Vitamin C is the most important vitamin in fruits and more than $90 \%$ of vitamin $\mathrm{C}$ in human diets are supplied by fruits, and vegetables. These vitamins work both or synergistically to prevent or delay oxidative reaction that lead to degenerative disease [22]. However, this study revealed that pomegranate juice contained low level of vitamin $\mathrm{E}$ $(0.07 \pm 0.01 \mathrm{mg} / 100 \mathrm{~g})$. 
Citation: Anahita A, Asmah R, Fauziah O (2015) Evaluation of Total Phenolic Content, Total Antioxidant Activity, and Antioxidant Vitamin Composition of Pomegranate Seed and Juice . General Med 3: 1000164. doi:10.4172/2327-5146.1000164

Page 4 of 4

\begin{tabular}{|l|l|}
\hline Parameter & Juice \\
\hline Vitamin C $(\mathrm{mg} / 100 \mathrm{~g})$ & $57.8 \pm 0.59$ \\
\hline Vitamin A $(\mu \mathrm{g} / 100 \mathrm{~g})$ & $22.8 \pm 0.69$ \\
\hline Vitamin E $(\mathrm{mg} / 100 \mathrm{~g})$ & $0.07 \pm 0.01$ \\
\hline
\end{tabular}

8. Cao G, Russell RM, Lischner N, Prior RL (1998) Serum antioxidant capacity is increased by consumption of strawberries, spinach, red wine or vitamin C in elderly women. J Nutr 128: 2383-2390.

9. Lee MK, Bok SH, Jeong TS, Moon SS, Lee SE, et al. (2002) Supplementation of naringenin and its synthetic derivative alters antioxidant enzyme activities of erythrocyte and liver in high cholesterolfed rats. Bioorg Med Chem 10: 2239-2244.

10. Opara UL, Al-Ani MR (2010) Antioxidant contents of pre-packed freshcut versus whole fruit and vegetables. British Food Journal 112: 797-810.

Table 3: Vitamin composition of pomegranate juice. Value expressed as mean \pm S.E.M; each value is a mean of triplicate reading

\section{Conclusions}

These findings suggested that pomegranate seed-juice has high level of phenolic content and antioxidant activity, which were positively correlated. Moreover, pomegranate juice could be acomplementary source of vitamin $\mathrm{C}$ and $\mathrm{A}$. In addition, the result concluded that the combination of seed and juice have higher antioxidant activity than two other parts (seed and juice) separately. Therefore, pomegranate seed-juice has possessed a potential source of natural antioxidant; which can be used as treatment for chronic diseases relative to overproduction of free radicals.

\section{Acknowledgement}

The authors wish to thank Department of Nutrition and Dietetics, Faculty of Medicine and Health Sciences, Universiti Putra Malaysia for their support and facilities.

\section{References}

1. Langley P (2000) Why a pomegranate? BMJ 321: 1153-1154.

2. Lansky EP, Newman RA (2007) Punica granatum (pomegranate) and its potential for prevention and treatment of inflammation and cancer. J Ethnopharmacol 109: 177-206.

3. Li Y, Guo C, Yang J, Wei J, Xu J, et al. (2006) Evaluation of ?antioxidant properties of pomegranate peel extract in comparison with pomegranate pulp extract. Journal of Food Chemistry 96: 254-260.

4. Viuda-Martos M, Ruiz-Navajas Y, Fernández-López J, Pérez-Alvarez JA (2011) Spices as functional foods. Crit Rev Food Sci Nutr 51: 13-28.

5. Fang YZ, Yang S, Wu G (2002) Free radicals, antioxidants, and nutrition. Nutrition 18: 872-879.

6. Jacob RA (1995) The integrated antioxidant system. Journal of Nutrition Research 15: 755-766.

7. Guo CJ, Yang JJ (2001) Progress in the study of antioxidant capacity of fruits and vegetables. China Public Health Journal 17: 87- 88

11. Singleton VL, Rossi JL (1965) Calorimetry of total phenolics with phosphomolybdic-phosphotungstic acid reagents. The American Journal of Enology and Viticulture 16: 144-158.

12. Benzie IF, Strain JJ (1996) The ferric reducing ability of plasma (FRAP) as a measure of "antioxidant power": the FRAP assay. Anal Biochem 239: 70-76.

13. Tee ES, Kuladevan R, Young SI, Khor SC, Zakiyah HO (1996) Nutrient analysis of foods. Report of the Institute Medical for Research. Kuala Lumpur: Institute Medical for Research.

14. Abdulnabi AA, Emhemed AH, Hussein GD, Biacs PA (1997) Determination of antioxidant vitamin in tomatoes. Journal of Food Chemistry 60: 207-212.

15. Ismail A, Cheah SF (2003) Determination of Vitamin C, b-carotene and Riboflavin Contents in Five Green Vegetables Organically and Conventionally Grown. Malays J Nutr 9: 31-39.

16. Gil MI, Tomás-Barberán FA, Hess-Pierce B, Holcroft DM, Kader AA (2000) Antioxidant activity of pomegranate juice and its relationship with phenolic composition and processing. J Agric Food Chem 48: 4581-4589.

17. Bravo L (1998) Polyphenols: chemistry, dietary sources, metabolism, and nutritional significance. Nutr Rev 56: 317-333.

18. Naveena BM, Sen AR, Kingsly RP, Singh DB, Kondaiah N (2008) Antioxidant activity of pomegranate rind powder extract in cooked chicken patties. International Journal of Food Science and Technology 43: $1807-1812$

19. Mousavinejad G, Emam DZ, Rezaei K, Khodaparast MH (2009) Identification and quantification of phenolic compounds and their effects on antioxidant activity in pomegranate juices of eight Iranian cultivars. Journal of Food Chemistry 115: 1274-1278.

20. Tezcan F, Gultekin OM, Diken T, Ozcelik B, Erim FB (2009) Antioxidant activity and total phenolic, organic acid and sugar content in commercial pomegranate juices. Journal of Food Chemistry 115: 873-877.

21. Davey MW, Van Montagu M, Inze D, Sanmartin M, Kanellis A, et al. (2000) Plant L-ascorbic acid: chemistry, function, metabolism, bioavailability, and effects of processing. Journal of Science Food and Agriculture 80: 825-860.

22. Elliot JG (1999) Application of antioxidant vitamins in foods and beverages. Journal of Food Technology 53: 46-48. 